\title{
Spotlight failure in covert visual orienting
}

\author{
RAYMOND KLEIN \\ Dalhousie University, Halifax, Nova Scotia, Canada \\ and \\ EDWARD HANSEN \\ Acadia University, Wolfuille, Nova Scotia, Canada
}

\begin{abstract}
An important property of visual orienting is that the metaphorical "beam" is aimed at a location in space, and should therefore affect performance on any stimuli that occur at attended (producing benefits) or nonattended (producing costs) locations. Three experiments are reported that challenge this property. We used a precuing paradigm in which centrally presented arrows indicated the likely location of a probable stimulus event, which the subject had to discriminate from an improbable event. In each experiment the probable stimulus-response pairing showed significant cuing effects (costs + benefits), whereas the improbable stimulus-response pairing did not. This finding suggests that covert endogenous (centrally presented cues) orienting is not well characterized by the spotlight metaphor. Under these conditions, subjects seem to be generating a more specific expectancy.
\end{abstract}

It is widely accepted that attention can be allocated in visual space in accordance with instructions or expectations (Eriksen \& Hoffman, 1972; Posner, 1978). The cost/benefit paradigm has produced a large and fairly coherent body of data, which has led to the widespread acceptance of a "spotlight" metaphor for describing properties of covert orienting. ${ }^{1}$ In this paradigm the subject receives a cue (e.g., an arrow at fixation) that provides information about the likely location of the imperative stimulus. Eye position is monitored to ensure that the observer maintains fixation. It is usually found that, compared with performance in a neutral condition (" +" at fixation) in which no expectancy is induced, performance is faster and/or more accurate for stimuli at expected locations (benefits) and slower and/or less accurate for stimuli at unexpected locations (costs). We will use the phrase covert endogenous orienting (Posner, 1980) to refer to the ability to shift attention away from fixation, which is suggested by this pattern of results. Covert refers to the absence of eye movements; endogenous refers to the strategic nature of the shifts, in contrast to the reflexive (exogenous) shifts that might be produced by contrast changes in the periphery (Jonides, 1981). During the time that empirical support was accumulating for the spotlight metaphor as a model for covert endogenous orienting (Posner, Snyder, \& Davidson, 1980), we conducted a series of studies challenging the most basic of spotlight properties. These will be described in their original chronology.

All of the studies reported here were presented in 1979 (Klein \& Hansen, 1979a, 1979b). This research was supported by grants to the first author from the Natural Sciences and Engineering Research Council of Canada. Requests for reprints can be directed to Raymond Klein, Department of Psychology, Dalhousie University, Halifax, NS B3H 4J1, Canada, or Edward Hansen, Department of Psychology, Acadia University, Wolfville, NS BOP 1X0, Canada.
In a previous paper, Klein (1980) proposed that when an observer desires to attend to a spatial location without eye movements, he/she gets ready to fixate the location, and the associated oculomotor readiness enhances processing from the to-be-fixated region. Two major predictions from this hypothesis were clearly disconfirmed, and the hypothesis was rejected. ${ }^{2}$ One finding from this set of studies was thought to be potentially problematic for the spotlight metaphor. If covert orienting is like a beam that illuminates the attended location, then (1) performance on all stimuli occurring at that location should benefit, and (2) performance on all stimuli occurring at nonattended locations should suffer. However, Klein (1980, Experiment 2) found that saccadic responses to occasional stimuli were unaffected by the presumed locus of attention as directed by the central cues and as indicated by performance on a primary, luminance detection task. We refer to this pattern of results as "spotlight failure."

Klein (1980) proposed two explanations for spotlight failure. One explanation relied on the distinction between two visual systems, one mediating conscious identification of shape and form, the other mediating localization. One explanation was that "attention operates on the conscious detection pathways"' (p. 274), in which case saccadic eye movement responses may be unaffected by covert orienting. The second explanation was that "attention may be allocated not to a position in space but to the set of known properties of the expected stimulus" (p. 274). This view was tenable because the stimuli requiring saccadic responses were both unlikely on an absolute basis and equally likely to occur at the two locations regardless of the cue. The purpose of the series of experiments described here was to replicate this effect and to distinguish between these two explanations. 


\section{GENERAL METHOD}

\section{Subjects}

Dalhousie University graduate or undergraduate students were paid $\$ 3 /$ hour (minimum wage in 1979) for participating. All had normal uncorrected vision. Subjects were assigned randomly to groups within experiments and were run in three to five sessions lasting about $1 \mathrm{~h}$ each. There were 6 subjects in each experiment.

\section{Apparatus \\ Each subject sat with his/her head in a chinrest and faced a Tek- tronix 604 oscilloscope with a fast phosphor at a distance of $45 \mathrm{~cm}$. A Biometrics (SGHV2) eye movement monitor was used to monitor horizontal eye position. A response bar with a microswitch was placed on the table in front of the subject. A DEC PDP 11-10 computer con- trolled the experimental events.}

\section{Task and Procedure}

Eye calibration was carried out immediately before and after each block of trials. At the start of each trial, the display consisted of three horizontally arranged dots. The middle dot was the fixation stimulus, and the peripheral dots ( $4^{\circ}$ from fixation) indicated the potential imperative stimulus locations. Subjects initiated each trial by depressing (and holding down) the response bar with both forefingers when they were fixating the central dot and ready for the trial to begin. A warning cue appeared at fixation $\mathbf{5 0 0} \mathrm{msec}$ later, and sampling of eye position was initiated. The warning cue could be a plus sign or an arrow pointing to the right or left. One second after onset of the cue, one of three possible events occurred: (1) one of the peripheral dots brightened (increased in refresh rate) for $100 \mathrm{msec}$, (2) an asterisk was superimposed on one of the peripheral dots for $1 \mathrm{sec}$, or (3) no stimulus was presented (catch trial). The frequency with which the different events followed the different cues is indicated for each experiment in Table 1 . Subjects were allowed $1 \mathrm{sec}$ to respond to the imperative stimuli.

There were two types of response: manual, which involved releasing the response bar in response to the brightness increment, and saccadic, which involved shifting gaze to the left or right target location following the appearance of an asterisk. The correct saccade direction was fixed for a given subject, and did not depend on the location of the asterisk. Following each trial, the experimenter (in an adjoining room) was informed about the type of trial and the subject's performance, and was shown a recording of the eye position. Feedback indicated a variety of possible errors (TOO SLOW-no response within $1 \mathrm{sec}$; TOO FASTresponse before stimulus or on catch trial; HAND ERROR-manual response when saccade was required; EYE ERROR-saccadic response when manual was required or saccadic response in wrong direction; EYE SHIFT ERROR-shift in eye position greater than $.5^{\circ}$ during the warning interval), or, following errorless trials, reaction time (RT) feedback or the word CORRECT was displayed. Subjects were informed of the likeli-

Table 1

Cue-Stimulus Frequencies for Each Experiment

\begin{tabular}{crrrrr}
\hline & \multicolumn{7}{c}{ Manual } & \multicolumn{2}{c}{ Saccadic } & Catch \\
\cline { 2 - 6 } Cue & L & R & L & R & Trial \\
\hline & \multicolumn{5}{c}{ Experiment $1(3)$} \\
+ & 20 & 20 & 10 & 10 & \\
$\leftarrow$ & 36 & 4 & 16 & 4 & 8 \\
$\rightarrow$ & 4 & 36 & 4 & 16 & 8 \\
& & & Experiment $2(2)$ & & \\
+ & 15 & 15 & 15 & 15 & \\
$\leftarrow$ & 24 & 6 & 24 & 6 & 8 \\
$\rightarrow$ & 6 & 24 & 6 & 24 & 8 \\
& & & Experiment $3(3)$ & & 8 \\
+ & 4 & 4 & 16 & 16 & \\
$\leftarrow$ & 4 & 4 & 28 & 4 & 4 \\
$\rightarrow$ & 4 & 4 & 4 & 28 & 4 \\
\hline
\end{tabular}

Note-Number of experimental blocks entering into the analyses are shown in parentheses. $L=$ left. $R=$ right. hood of the events for each block of trials and of how these likelihoods were affected by the presentation of the different cues (Table 1), and they were urged to shift attention in response to cues without moving their eyes. We use the terms valid and invalid to refer to trials in which stimuli occurred at the location indicated or not indicated by the arrow, respectively. Trials with a plus sign as the cue are referred to as neutral.

On Day 1 , subjects were given practice on each task separately (about 60 trials each, with the same cue-stimulus probabilities as they would experience when the tasks were combined), followed by a practice block in which the tasks were combined. On the remaining days, subjects received practice (combined for Experiments 1 and 2, separate for Experiment 3) prior to the experimental block. If error rates or eye shift errors were very high in a particular session, the subject was asked to repeat that session. The data from Day 1 , repeated sessions, and all practice trials were excluded from the analyses.

\section{EXPERIMENT 1}

The most important difference between this study and Klein's (1980, Experiment 2) is that in Klein's the cues were uninformative about the location of the unlikely stimuli requiring saccadic responses, whereas in the present study the cues carried probabilistic information about the locations of likely and unlikely stimuli (see Table 1). In addition, in Klein's study half of the subjects moved toward an asterisk and half moved away; that is, for the saccadic responses subjects made a choice on the basis of location of the stimulus. In the present study half of the subjects moved to the right and half moved to the left, regardless of the location of the asterisk. The reason for this change was to make the saccadic component of the task more equivalent to the manual luminance detection component, which also involved only a single response. RT feedback was provided only for the manual task.

\section{Results and Discussion}

Mean RT for the saccadic and manual responses are shown in Figure 1a. Analyses of variance (ANOVAs) revealed a significant effect of expectancy on the manual RTs $[F(2,8)=22.1, p<.001]$, with roughly equal costs and benefits, whereas the effect of expectancy on saccadic responses was not significant $(F<1)$. No other effect in either analysis was significant. Analysis of manual response accuracy revealed no significant effects; however, in the analysis of saccadic accuracy, there was a significant effect of prime condition $[F(2,8)=15.4$, $p<.001$ ]. More errors were made in the valid (14.1) than in the invalid condition (5.6), and errors in the neutral condition fell in the middle (8.9).

The changes made in this study did not alter the pattern of results obtained by Klein (1980, Experiment 2). The spotlight failure effect was observed even though the cues were now informative for the saccadic task and the choice component of that task had been eliminated.

\section{EXPERIMENT 2}

The results of Experiment 1 seem to support the twovisual-system notion that saccadic responses may not be sensitive to attention. However, two remaining differences 


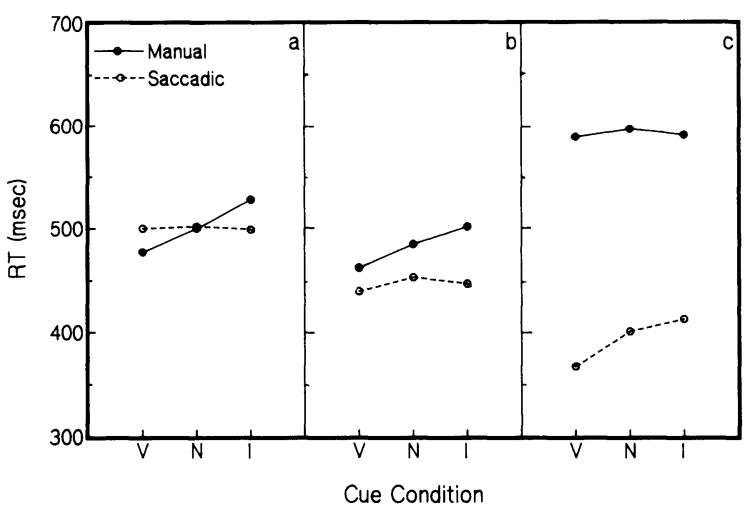

Figure 1. Reaction time results from the three experiments: (a) Experiment 1 (manual likely, saccadic unlikely), (b) Experiment 2 (manual and saccadic equally likely), (c) Experiment 3 (saccadic likely, manual unlikely). In all panels, valid (V) refers to stimuli occurring on the side indicated by an arrow cue, invalid (I) to stimuli occurring on the opposite side, and neutral (N) to trials with a " + " cue. See Table 1 for cue-event frequencies.

between the saccadic and manual tasks might be responsible: (1) stimulus-response probability, which was lower for the saccadic task than for the manual, and (2) the fact that RT feedback was provided for the manual but not the saccadic task. Both of these differences were eliminated in Experiment 2.

\section{Results and Discussion}

Mean RT for the saccadic and manual responses are shown in Figure 1b. ANOVAs revealed a significant effect of expectancy on the manual RTs $[F(2,8)=11.65$, $p<.005]$ but not on the saccadic responses $(F<1)$. $^{3}$ In the accuracy ANOVAs the effect of prime condition was not significant for either the saccadic or the manual task. Once again, we have obtained evidence of covert orienting only for stimuli requiring a manual response; those requiring a saccadic response seem to be insensitive to the expectancy manipulation.

\section{EXPERIMENT 3}

The view that eye movement responses may not show the effects of attentional allocation seems strongly indicated by our results. A striking way to demonstrate this would be to make the saccadic task likely and primed, and the manual task unlikely and unprimed. ${ }^{4}$ Subjects may orient their attention in response to the conditional probability information the cues provide about the saccadic stimuli, but these stimuli will show no effects; only the manual stimuli, for which the cues are uninformative, will show costs and benefits. Thus, the major differences between this and the preceding experiments are that the saccadic stimuli/responses are the more likely, and that the cues have no significance for the unlikely (manual) stimuli/responses.

\section{Results and Discussion}

Mean RT for the saccadic and manual responses are shown in Figure 1c. ANOVAs revealed a significant effect of expectancy with the saccadic responses $[F(2,8)=$ $9.07, p<.001]$ and no effect of expectancy with manual responses $(F<1)$. The analysis of accuracy did not reveal any effects that contradict these trends. Contrary to the prediction based on the two-visual-system notion, saccadic responses did show expectancy effects. Spotlight failure is obtained with the improbable and uncued manual detection stimuli; the intermixed stimuli requiring saccadic responses show typical effects of attention.

\section{GENERAL DISCUSSION}

Our studies produced a pattern of results that is inconsistent with a fundamental property of visual orienting that is implied by a spotlight metaphor and that is assumed by many investigators: performance with some stimuli is affected by whether they occur at what appears to be an attended or unattended location, whereas performance with other stimuli is not so affected. This pattern is summarized in Table 2.

By comparing the patterns from Klein (1980, Experiment 2) and from Experiment 3 of this study, it can be seen that whether the response is manual or saccadic and whether the stimulus is brief or long is of little consequence for the spotlight failure effect. ${ }^{5}$ In both cases, the unlikely stimulus whose location is not predicted by the cue shows evidence of spotlight failure. The results of Experiments 1 and 2 seem to indicate that it is not the validity of the cues for these unlikely stimulus-response pairings that is important, and subsequent work (Hansen, 1987; Hansen \& Klein, 1983) supports this claim. This work, which used one or two different manual responses,

Table 2

Summary of Results from Manual/Saccadic Choice Experiments

\begin{tabular}{|c|c|c|c|c|c|c|}
\hline \multirow[b]{2}{*}{ Experiment } & \multicolumn{2}{|c|}{ Stimulus } & \multirow{2}{*}{$\begin{array}{c}\text { Response } \\
\text { Type }\end{array}$} & \multirow{2}{*}{$\begin{array}{c}\text { Stimulus/Response } \\
\text { Likelihood }\end{array}$} & \multirow{2}{*}{$\begin{array}{c}\text { Cue } \\
\text { Informative? }\end{array}$} & \multirow{2}{*}{$\begin{array}{l}\text { Cost }+ \\
\text { Benefit }\end{array}$} \\
\hline & Form & Duration & & & & \\
\hline Klein (1980) & $\underset{*}{\substack{\text { Bright } \\
*}}$ & $\begin{array}{r}100 \mathrm{msec} \\
1000 \mathrm{msec}\end{array}$ & $\begin{array}{l}\text { Manual } \\
\text { Saccadic }\end{array}$ & $\begin{array}{l}80 \\
20\end{array}$ & Yes & Yes \\
\hline E1 & $\underset{*}{\text { Bright }}$ & $\begin{array}{r}100 \mathrm{msec} \\
1000 \mathrm{msec}\end{array}$ & $\begin{array}{l}\text { Manual } \\
\text { Saccadic }\end{array}$ & $\begin{array}{l}67 \\
33\end{array}$ & $\begin{array}{l}\text { Yes } \\
\text { Yes }\end{array}$ & $\begin{array}{l}\text { Yes } \\
\text { No }\end{array}$ \\
\hline E2 & $\underset{*}{\text { Bright }}$ & $\begin{array}{r}100 \mathrm{msec} \\
1000 \mathrm{msec}\end{array}$ & $\begin{array}{l}\text { Manual } \\
\text { Saccadic }\end{array}$ & $\begin{array}{l}50 \\
50\end{array}$ & $\begin{array}{l}\text { Yes } \\
\text { Yes }\end{array}$ & $\begin{array}{l}\text { Yes } \\
\text { No }\end{array}$ \\
\hline E3 & $\begin{array}{c}\text { Bright } \\
*\end{array}$ & $\begin{array}{l}100 \mathrm{msec} \\
1000 \mathrm{msec}\end{array}$ & $\begin{array}{l}\text { Manual } \\
\text { Saccadic }\end{array}$ & $\begin{array}{l}20 \\
80\end{array}$ & $\begin{array}{l}\text { No } \\
\text { Yes }\end{array}$ & $\begin{array}{l}\text { No } \\
\text { Yes }\end{array}$ \\
\hline
\end{tabular}


demonstrates that the critical factor for observing spotlight failure is an unlikely stimulus-response combination. An unlikely stimulus that must be discriminated from a likely one may not show the effects of attention. This pattern is consistent with an explanation in terms of an attentional mechanism that is sensitive to the conjunction of attributes of the likely stimulus. For this mechanism, location does not have the special status that is implied by the spotlight metaphor. A related explanation might involve the setting of decision criteria in accordance with the relative likelihood that a particular stimulus may occur in one or the other location (e.g., Shaw, 1984). This explanation has difficulty dealing with the failure to find cuing effects for a stimulus-response pair when the cues are informative about the location of that stimulus event (Hansen, 1987; Experiments 1 and 2 presented here).

In conclusion, four separate studies have observed a failure of the hypothetical spotlight to illuminate the attended location in a choice task situation. Subsequent work has demonstrated that this effect is not due to the combination of manual and saccadic responses, which might be regarded as unique. Thus, covert orienting of visual attention in response to centrally presented cues is not well characterized by a spotlight that is pointed at the cued location. ${ }^{6}$ Instead, we believe that subjects generate an expectancy for (or activate the pathway representing) the conjunction of attributes of the likely event. Further work will be necessary to determine the boundary conditions for this spotlight failure. For example, would our pattern of results obtain if peripheral cues were used to elicit exogenous shifts of attention? We think not. There is good reason to believe that central and peripheral cues do not orient the same mechanisms (Briand \& Klein, 1987), and preliminary data from our laboratory suggest that spotlight failure is not observed when peripheral cues are used.

\section{REFERENCES}

Briand, K. A., \& KLEIN, R. M. (1987). Is Posner's "beam" the same as Treisman's "glue"?: On the relationship between visual orienting and feature integration theory. Journal of Experimental Psychology: Human Perception \& Performance, 13, 228-241.

ERIKSEN, C. W., \& HofFMAN, J. E. (1972). Some characteristics of selective attention in visual perception determined by vocal reaction time. Perception \& Psychophysics, 11, 169-171.

HANSEN, E. F. (1987). Dual response analysis of cognitive control of visual attention. Unpublished doctoral dissertation, Dalhousie University, Halifax, Nova Scotia, Canada.

HaNSEN, E. F., \& Klein, R. M. (1983, August). Dual task analysis of cognitive control of visual attention. Paper presented at the meeting of the American Psychological Association, Anaheim, California.

JONIDES, J. (1981). Voluntary versus automatic control over the mind's eye's movement. In J. Long and A. Baddeley (Eds.), Attention and performance IX. Hillsdale, NJ: Erlbaum.

KLEIN, R. M. (1980). Does oculomotor readiness mediate cognitive control of visual attention? In R. S. Nickerson (Ed.), Attention \& performance VIII. Hillsdale, NJ: Erlbaum.

KLEIN, R. M., \& BRIAND, K. A. (1986, May). Allocation of attention in visual space. Paper presented at Banff Annual Seminar in Cognitive Sciences, Banff, Alberta, Canada.
KLeIN, R. M., \& HANSEN, E. F. D. (1979a, November). On the relationship between shifts of attention and gaze. Paper presented at the meeting of the Psychonomic Society, Phoenix, Arizona.

KLeIN, R. M., \& HANSEN, E. F. D. (1979b, April). Shifts in attention and gaze: Evidence for independence. Paper presented at the meeting of the Association for Research in Vision and Ophthalmology, Sarasota, Florida.

LABERGE, D. (1983). Spatial extent of attention to letters and words. Journal of Experimental Psychology: Human Perception \& Performance, 9, 371-380.

LAMBERT, A. J. (1987). Expecting different categories at different locations and spatial selective attention. The Quarterly Journal of Experimental Psychology, 39(A), 61-67.

LAMBERT, A. J., \& HoCKeY, G. R. J. (1986). Selective attention and performance with a multidimensional visual display. Journal of $E x-$ perimental Psychology: Human Perception \& Performance, 12, 484-485.

Podgorny, P., \& ShePard, R. N. (1983). Distribution of visual attention over space. Journal of Experimental Psychology: Human Perception \& Performance, 9, 380-393.

PosNer, M. I. (1978). Orienting. Chronometric explorations of the mind (pp. 185-215). New York: Wiley.

POSNER, M. I. (1980). Orienting of attention. Quarterly Journal of Experimental Psychology, 32, 3-25.

Posner, M. I., SNyder, C. R. R., \& Davidson, B. J. (1980). Attention and the detection of signals. Journal of Experimental Psychology: General, 109, 160-174.

REEVES, A., \& SPERUNG, G. (1986). Attention gating in short term visual memory. Psychological Review, 93, 180-206.

SHAw, M. L. (1984). Division of attention between spatial locations: A fundamental difference between detection of letters and detection of luminance increments. In H. Bouma \& D. G. Bouwhuis (Eds.), Attention and performance X: Control of language processes. Hillsdale, NJ: Erlbaum.

ShePARD, M., Findlay, J. M., \& Hockey, R. J. (1986). The relationship between eye movements and spatial attention. Quarterly Journal of Experimental Psychology, 38(A), 475-491.

\section{NOTES}

1. Although other paradigms (LaBerge, 1983; Podgorny \& Shepard, 1983; Reeves \& Sperling, 1986) have been used to study the distribution of visuo-spatial attention, it is not clear whether they are exploring the same mechanisms of attention that are elicited in the cost/benefit paradigm (Klein \& Briand, 1986).

2. In light of recent findings (Shepard, Findlay, \& Hockey, 1986), a reexamination of this issue may be appropriate.

3. For both responses, RTs were faster when the target stimulus occurred at the location to be fixated if an asterisk appeared $[F(1,4)=$ $16.2, p<.025$, for manual; $F(1,4)=8$. $p<.05$, for saccadic]. This finding contradicts Klein's (1980) Experiment 1, and is consistent with the notion that when one prepares to make an eye movement to a location, stimuli there are detected more efficiently. However, since this effect is absent in Experiments 1 and 3, we do not want to place too much emphasis on it.

4. We thank John Barresi for suggesting this experiment.

5. By testing saccadic and manual responses separately using brightness increments that lasted either $100 \mathrm{msec}$ or $1,000 \mathrm{msec}$, we subsequently confirmed this conclusion in a single task situation. The cuing effect (invalid minus valid) was larger with saccadic $(38 \mathrm{msec}$ ) than with manual $(25 \mathrm{msec})$ responses and was unaffected by stimulus duration.

6. Recently, Lambert (1987; Lambert \& Hockey, 1986) drew a similar conclusion. One important difference between his studies and ours is that our subjects were precued to attend a particular location, whereas his subjects were precued to expect a particular shape, which, if presented, was more likely to occur at one location than the other. Therefore, our demonstration of "spotlight failure"' is somewhat more damaging to the spotlight metaphor since, unlike Lambert's, our attentional manipulation is explicitly spatial and the same as that used in much of the covert visual orienting literature. 